\title{
Divulgação científica e modelos explicativos: o intercâmbio de conhecimentos no cotidiano escolar
}

\author{
Paulo Roberto de Araújo Porto ${ }^{1}$ \\ Marta Ferreira Abdala Mendes ${ }^{1}$ \\ Wagner Francisco Marinho da Silva ${ }^{1}$ \\ Marcelo Paraiso Alves ${ }^{1,2}$
}

\begin{abstract}
Resumo
O conhecimento científico possui características epistemológicas próprias que pode dificultar seu entendimento por aqueles que não fazem parte da "comunidade científica". A construção de modelos explicativos é uma das estratégias de transposição desse conhecimento auxiliando o entendimento e a popularização da ciência. Baseando-se nesses pressupostos esse artigo descreve as etapas de um projeto de divulgação do conhecimento científico desenvolvido por estudantes do curso técnico em automação industrial IFRJ/campus Volta Redonda. O projeto constou de duas etapas: na primeira foram construídos modelos explicativos do núcleo de uma célula eucariótica e realizada uma pesquisa sobre anomalias relacionadas as estruturas nucleares, destacando-se as neoplasias. Essa etapa se desenvolveu durante o estudo desse conteúdo nas aulas de Biologia. A segunda etapa constou de uma mostra de ciência em duas escolas públicas e apresentação de uma sala temática na II Sematec Sul do IFRJ/ campus Volta Redonda, onde além dos modelos explicativos foi apresentada uma pesquisa sobre causas, diagnósticos e centro de atendimento aos portadores de neoplasias na cidade de Volta Redonda. A metodologia utilizada baseou-se na pesquisa-ação. Os resultados foram obtidos a partir da análise quantitativa das respostas dadas aos questionários aplicados durante a amostra de ciências e a II Sematec Sul. A análise dos resultados mostrou que o projeto contribui de forma significativa para o aprendizado do conteúdo tanto dos estudantes que desenvolveram o trabalho, como daqueles que participaram da mostra de ciência e II Sematec Sul.
\end{abstract}

Palavras-chave: modelos explicativos, núcleo celular, neoplasias, divulgação científica

\begin{abstract}
Scientific knowledge has its own epistemological characteristics that can hinder your understanding by those who are not part of the "scientific community". The construction of explanatory models is one of the strategies of translating this knowledge by assisting the understanding and the popularization of science. Based on these assumptions this article describes the steps of a project for the dissemination of scientific knowledge developed by students of the technical course in industrial automation IFRJ/campus Volta Redonda. The project consisted of two phases: in the first explanatory models were built the nucleus of a eukaryotic cell and performed a search on related nuclear structures anomalies, notably the neoplasms. This step has developed during the study of this content in Biology classes. The second stage consisted of a showcase of science in two public schools and a themed room in II Sematec Sul the IFRJ/ campus Volta Redonda, where in addition to the explanatory models was presented a survey on causes, diagnosis, and care centre for people with tumors in the city of Volta Redonda. The methodology used is based on action research. The results were obtained from the quantitative analysis of the responses to the questionnaires for the sample of science and II Sematec Sul. The analysis of the results showed that the project contributes significantly to the learning of the content both of students who developed the work, as those who participated in the exhibition of science and II Sematec Sul.
\end{abstract}

Keywords: explanatory models, cell nucleus, neoplasms, scientific dissemination

1 Instituto Federal do Rio de Janeiro - VR

2 Professor Doutor, Universidade Federal Fluminense-UFF e Mestrado Profissional em Ensino em Ciências e Meio Ambiente- UniFOA. 


\section{INTRODUÇÃO}

Dentro da proposta da Lei de Diretrizes e Bases da Educação Nacional (LDB), configurada nos Parâmetros Curriculares Nacionais do Ensino Médio (PCNEMs), percebe-se a relevância de aproximar o estudante da ciência e da tecnologia em todas as dimensóes da sociedade, oportunizando a ele uma concepção ampla e social do contexto científico-tecnológico. Os Parâmetros Curriculares Nacionais (PCN, 1998) definem "Ciência" como uma elaboração humana para a compreensão do mundo. Seus procedimentos devem estimular uma postura reflexiva e investigativa sobre os fenômenos da natureza e de como a sociedade nela intervém, utilizando seus recursos e criando uma nova realidade social e tecnológica. O objetivo principal do Ensino de Ciências passou a ser o oferecimento de condiçóes para o educando vivenciar o que se denomina método científico, a partir de observaçóes, levantamento de hipóteses, testagens, reinvençóes, e quando fosse o caso trabalhando de forma a produzir conhecimentos, assim sendo capaz de tomar decisões com bases em informaçóes e dados.

Outra questão que se coloca são os livros didáticos que se apresentam inadequados no tratamento pedagógico e científico, trazendo inúmeros conceitos e observaçóes - algumas vezes incorretos - prontos e desvinculados do mundo real do educando. E, ainda, Rogado (2004), reforça que o material didático tradicional parece bom para quem já sabe, não para quem vai aprender. Além disso, é grande o número de professores, que faz desse material a única e verdadeira fonte de informaçóes e critérios de organização dos conteúdos durante o trabalho pedagógico. Dessa forma, uma imagem irreal e fragmentada da Ciência é construída pelo estudante, tal concepção impede a construção progressiva e a integração de conceitos, dificultando a aprendizagem, reduzindo-a a simples memorização, tornando-a tediosa e desinteressante (ROGADO, 2004; MARIN, 1998).

Por outro lado os conteúdos programáticos previstos para o ensino das disciplinas relacionadas com a educação em ciência (Química, Física e Biologia), muitas vezes não permitem uma contextualização com os conhecimentos trazidos pelos estudantes. Construído em bases epistemológicas próprias e baseado no consenso entre os membros da comunidade científica, o conhecimento científico possui referências e linguagens específicas, distante daquela vivenciada pela maioria da população, por isso as estratégias que buscam uma melhoria no entendimento desse conhecimento podem ser valiosas no processo de ensino-aprendizagem.

$\mathrm{Na}$ intenção de superar tal reducionismo o trabalho busca a noção de Currículos Praticados (OLIVEIRA, 2003) na tentativa de visibilizar as práticas realizadas no cotidiano escolar. A referida noção procura priorizar a ação de ensinar e aprender a partir do diálogo estabelecido entre os currículos estabelecidos pelos órgãos oficiais, singularizando-os, por intermédio dos espaços ocupados pelo sujeito comum (professor, aluno, comunidade escolar em diálogo com o contexto social em que está inserido). Como menciona ALVES (2005), as práticas culturais são tecidas em redes de sujeitos e subjetividades como uma teia, com fios tecidos em contextos plurais entrelaçados, reinventando (CERTEAU, 1994) 'outras' práticas a partir dessas tessituras. Ao discutir os currículos praticados no cotidiano, Oliveira (2003, p. 68) menciona que:

É com Certeau que vamos, mais uma vez, buscar a compreensão das formas de criaçáo de alternativas curriculares, tentando evidenciar as "artes de fazer" daqueles a quem foi reservado o lugar da reproduçáo. (...) O cotidiano (...) aparece como espaço privilegiado de produção curricular, para além do previsto nas propostas oficiais.

Para a autora os currículos criados pelas práticas cotidianas emergem como um espaço privilegiado de fabricação de experiências, que concebidas para além do previsto nas propostas oficiais, apresentam processos de ensino e aprendizagem marcados por formas criativas e particulares, por meio das quais docentes buscam o aprendizados de seus educandos. Cada maneira de ensinar, cada conteúdo desenvolvido, cada experiência desenvolvida só pode ser entendida junto ao conjunto de circunstâncias que a torna possível, o que envolve a história local dos sujeitos mundanos em interaçáo. Oliveira (2003) reitera que pensar nessa ótica, nos encaminha para a percepção de práticas alternativas produzidas pelos educadores cotidianamente nas escolas e que estâo invisibilizados pelas concepçóes tradicionais de currículo.

Numa tentativa de seguir as trilhas de Oliveira (2003) e Certeau (1994), após discussão sobre os obstáculos a aprendizagem do conteúdo previsto no currículo de Ciências Biológicas, decidiu-se promover uma 'outra' possibilidade de aprendizagem: Foi proposto aos alunos do $2^{\circ}$ período do curso de automação industrial do IFRJ/campus Volta Redonda, no ano de 2010, a construção de modelos explicativos das estruturas do núcleo de uma célula eucariótica.

A utilização de modelos explicativos facilita a compreensão de alguns conteúdos, pois aproxima os estudantes do mundo da ciência. $\mathrm{O}$ ser humano se utiliza de modelos para explicar o mundo a sua volta, que são os denominados modelos mentais. Dentre as diferentes abordagens sobre as representaçôes internas, o conceito de modelo mental tem alcançado uma grande importância na pesquisa em Ensino de Ciências a partir da segunda metade dos anos 1990 (GRE- 
CA; MOREIRA, 2002). Na comunidade científica, também são produzidos modelos, que estão articulados a teorias e leis fazendo as ligações do conhecimento científico com o mundo real, dessa forma a modelização é introduzida como instância mediadora entre o teórico e o empírico. Os modelos são abordados na medida em que se procuram relaçóes entre as abstraçôes e os dados empíricos (PIETROCOLA, 2001). Um exemplo de modelização, na área da Biologia, foi quando, em 1953, James Watson, Francis Crick, Maurice Wilkins e Rosalind Franklin sugeriram uma representação tridimensional para explicar a estrutura da dupla hélice da molécula de DNA, o que certamente contribuiu para a aceitação, pela comunidade científica da época, da teoria formulada pelos mesmos. Hoje podemos representar tal estrutura através de modelos explicativos ou didáticos na sala de aula.

A utilização de modelos em educação em Ciências é relevante (COLINUAX, 1998). O uso adequado de modelos, a efetiva abordagem construtivista, o aporte epistemológico e a seleção de conteúdos programáticos estão entrelaçados e são referenciais norteadores no Ensino de Ciências, numa perspectiva de construção efetiva do conhecimento científico escolar (LORENZINI, ANJOS, 2004). Krasilchick (2004) salienta que os modelos didáticos são um dos recursos mais utilizados em aulas de biologia, para mostrar objetos em três dimensôes. No entanto, eles podem apresentar várias limitações, como fazer os estudantes entenderem que os modelos são simplificaçóes do objeto real ou fases de um processo dinâmico. Para diminuir essas limitaçôes e envolver o aluno no processo de aprendizagem, é importante que eles façam os próprios modelos. De acordo com Giordan, Vecchi (1996), um modelo é uma construção, uma estrutura que pode ser utilizada como referência, uma imagem analógica que permite materializar uma ideia ou um conceito, tornados assim, diretamente assimiláveis. Baseando-se nesses pressupostos e nas discussóes do grupo de pesquisa envolvido, ficou decidido, que os educandos fariam a construção de modelos explicativos após o estudo do conteúdo relacionado ao núcleo de uma célula eucariótica.

Quando os alunos são motivados a construir seus próprios modelos, baseando-se nos modelos científicos tradicionais, possibilita-se uma articulação entre o conhecimento científico e a sua visão de mundo. Permite-se uma aproximaçâo entre o "mundo científico" e o "mundo real dos alunos". Nesse contexto a criatividade pode trazer novas possibilidades de explicação facilitando o processo de ensino-aprendizagem e a popularização da ciência. Além disso, essa estratégia contextualiza a ciência, uma vez que os modelos científicos propostos pelos cientistas e pesquisados pelos alunos, baseiam-se em conhecimentos que traduzem o momento histórico vivenciado pelos cientistas e possíveis limitaçóes de sua época. Essas informaçóes permitem uma compreensão da ciência como uma construção social, sujeita a modificaçôes, desfazendo a informação de que a ciência é feita de verdades absolutas, hegemônica e capaz de dar respostas a todos os problemas vivenciados por nossa sociedade.

Nesse contexto também se possibilita uma discussão sobre Ciência Tecnologia e Sociedade (CTS). Os estudos CTS têm atribuído um papel importante para os aspectos históricos e epistemológicos da ciência e a interdisciplinaridade na alfabetização em ciência e tecnologia. Eles indicam a necessidade de explorar os conhecimentos sob um caráter mais amplo, tendo uma reflexão crítica ( ANGOTTI E AUTH, 2001).

Essa experiência que se iniciou como uma atividade pedagógica cujo objetivo era facilitar o entendimento dos educandos em relação ao conteúdo estudado na disciplina de Biologia, enredou-se aos diálogos e sugestôes dos professores e alunos, transformando-se em um projeto de divulgação do conhecimento científico, por meio da realização de uma pequena exposição dos modelos construídos em outras duas escolas, dentro de uma amostra de ciências. Dessa forma, o conhecimento produzido pelos alunos do IFRJ campus Volta Redonda, seria divulgado em espaços diferentes promovendo um intercâmbio de conhecimentos entre instituiçóes de ensino.

A realização de amostras de ciências e feira de ciências favorece a transposição dos conhecimentos científicos facilitando a compreensão dos mesmos de uma forma dinâmica, permitindo interaçáo dos educandos. Nesses momentos a interação e a troca de informaçóes entre aqueles que apresentam o conhecimento e os visitantes torna-se um momento de aprendizado. Certamente essa estratégia contribuiu para um melhor entendimento dos conteúdos programáticos propostos nas disciplinas voltadas para o Ensino de Ciências.

Assim, torna-se relevante explicitar que esse artigo procurou analisar os desdobramentos das açóes do projeto anunciado e, simultaneamente, investigar a influência dos modelos explicativos no processo de aprendizagem estabelecido na fabricação dos modelos e na realizaçáo da amostra de ciências.

\section{METODOLOGIA}

Esse projeto se dividiu em três etapas: construção dos modelos explicativos do núcleo celular, organização e realização de uma amostra de ciências em duas escolas públicas do município de Volta Redonda e, por fim, a apresentação do projeto na II Sematec Sul - IFRJ-VR, no ano de 2010. Nas duas últimas etapas foram utilizados os modelos explicativos construídos pelos estudantes.

Tendo em vista a busca de estratégias alternativas de aprendizagem, buscou-se no primeiro momento motivar 
os alunos do $2^{\circ}$ período do Curso Técnico em Automação Industrial, para a construção dos modelos explicativos relacionados ao conteúdo "núcleo celular" estudado na disciplina de Biologia. Essa motivação iniciou-se com uma discussão sobre a importância dos modelos explicativos para o estudo de algumas estruturas celulares, principalmente as microscópicas. Foi citado entre outros, o impacto da construção do modelo tridimensional da molécula de DNA por Watson e Circk na década de 1950. O trabalho foi desenvolvido em duas turmas durante as aulas de biologia. As turmas tinham em média 22 alunos e se mostravam muito participativas nas atividades propostas no decorrer da aula. No primeiro momento a proposta era construir os modelos explicativos na expectativa de facilitar o estudo do conteúdo proposto em aula. Cada turma foi dividida em equipes de aproximadamente quatro alunos e o conteúdo foi dividido em cinco temas diferentes. Isso possibilitou que cada turma pesquisasse temas diferenciados, por outro lado o mesmo tema foi pesquisado por duas equipes, uma de cada turma. A orientação era que cada equipe propusesse a construção de um modelo explicativo relacionado ao tema estudado, que seria apresentado durante um seminário

O trabalho foi se desenvolvendo e nas aulas posteriores as equipes traziam dúvidas sobre as propostas que estavam desenvolvendo. Ficou evidenciado que a maior parte dos alunos optou pela construção de modelos tridimensionais. Ao finalizar o primeiro momento, os modelos foram apresentados na sala de aula e avaliados. Houve uma interação com os demais colegas que sugeriram melhorias tanto nos modelos quanto na explicação do conhecimento apresentado pelas equipes. Essa dinâmica motivou um desafio maior: utilizar os modelos construídos pelas equipes para a realização de uma pequena amostra de ciências em duas outras escolas públicas do ensino médio. Essa decisão foi tomada porque os educandos perceberam que a produção dos modelos auxiliou a compreensão do conteúdo estudado e que essa experiência poderia ser utilizada em outro espaço.

A partir dessa proposta foi organizada a amostra de ciências em duas escolas públicas do município de Volta Redonda. As amostras de ciências foram organizadas respeitando-se os diferentes temas pesquisados e as diferentes formas de apresentação dos mesmos, proporcionando um trabalho diversificado e dinâmico, além disso, é relevante frisar que a amostra foi constituída de acordo com a disponibilidade de espaço e recursos de cada unidade escolar. Foi possível montar nas exposiçóes os modelos tridimensionais, realizar experimentos, jogos e paródias. Dessa forma os alunos realizaram um intercâmbio de conhecimentos com seus colegas de outras escolas publicas

Todas as atividades foram organizadas e aplicadas pelos estudantes do $2^{\circ}$ período do curso de automaçấo do IFRJ campus Volta Redonda. Após a apresentação da amostra de ciências os alunos que participaram do trabalho preencheram um questionário que investigava a proposta desenvolvida em suas escolas. Os questionários utilizados foram analisados pelo comitê de ética local. Por se tratar de um trabalho realizado por educandos para outras unidades educacionais, houve também uma avaliação dos alunos do IFRJ campus Volta Redonda, que elaboraram e apresentaram a amostra de ciências. De acordo com os dados obtidos pode-se indicar que a atividade desenvolvida pelos estudantes possibilitou uma aprendizagem significativa. A aprendizagem significativa nesse estudo é entendida como "o mecanismo humano, por excelência, para adquirir e armazenar a vasta quantidade de ideias e informaçóes representadas em qualquer campo de conhecimento" (AUSUBEL, 1963, p. 58).

Para a conclusão do projeto foi feita uma apresentação dos trabalhos na II Sematec Sul (IFRJ-VR). Durante o evento realizou-se uma divulgaçáo do conhecimento cientifico, onde o conteúdo estudado e apresentado nas amostras de ciências foi contextualizado com a abordagem das neoplasias. A estratégia utilizada para a apresentação do trabalho foi a montagem de uma sala temática, que foi dividida em quatro espaços diferentes: no primeiro foram apresentados os modelos explicativos do núcleo celular, permitindo aos visitantes uma identificação das características dessa parte da célula. Durante a abordagem das estruturas do núcleo celular, o DNA recebia um destaque especial, devido sua relação com as neoplasias. Em seguida havia um espaço dedicado a informaçóes sobre as causas de algumas neoplasias e os tipos mais comuns em nossa região. Seguiam-se informaçóes sobre centros de tratamentos dos doentes na nossa cidade e região. Finalmente eram apresentados os grupos de apoio aos portadores de câncer existentes na nossa cidade. Essas informaçôes foram obtidas através de pesquisas e visitas aos centros de tratamento. Essa etapa do projeto teve um caráter de utilidade pública ao levar para a comunidade informaçóes relevantes a respeito de uma doença que despertou grande interesse aos visitantes da sala temática.

Pretendeu-se elaborar, demonstrar e contextualizar o conhecimento científico buscando uma possibilidade de divulgação da ciência e contribuição para a alfabetização científica.

\section{RESULTADOS:}

A apresentação dos resultados realizar-se-á a partir dos três momentos que se desdobrou o projeto de modelos explicativos: no primeiro momento discutiremos o trabalho realizado pelos educandos na construção e apresentação dos modelos explicativos na sala de aula. No segundo momento a discussão permanecerá centrada na avaliação do trabalho realizado na mostra de ciências, onde os educandos do IFRJ-VR 
interagiram com estudantes de outras escolas. Nessa etapa os dados obtidos a partir das percepçóes dos discentes das escolas visitadas serão apresentados. Por fim, o terceiro momento apresentaremos os resultados obtidos durante a apresentação do projeto na II Sematec Sul do IFRJ-VR.

A construção dos modelos pelos estudantes refletiu de forma significativa no aprendizado dos conteúdos relacionados ao núcleo da célula eucariótica, e isso foi percebido por meio de indícios nos resultados obtidos nas avaliaçóes que investigavam o conhecimento relacionado a esse tema após a apresentação dos trabalhos. Foi possível observar que os educandos do IFRJ-VR, apresentaram uma melhoria qualitativa na descrição das diferentes partes do núcleo celular bem como das funçóes que cada uma desempenha na célula eucariótica. A observação decorreu pelo resultado das avaliaçóes que foram realizadas antes e depois do desenvolvimento do projeto. É relevante considerar que ao construir os modelos explicativos os educandos tiveram a oportunidade para aprofundar os conhecimentos que adquiriram antes da construção dos modelos explicativos.

A apresentação da amostra de ciências, pelos alunos, demonstrou outros conhecimentos aprendidos pelos educandos: a organização e o planejamento necessários para a realização da amostra. Durante a organização do evento foi possível perceber que os educandos demonstravam segu- rança e domínio teórico na apresentação do conteúdo e no esclarecimento das dúvidas apresentadas pelos educandos e professores das outras escolas. Essa amostra foi organizada em duas escolas que chamaremos de escola A e escola B. Em cada uma das duas escolas foram utilizados dois espaços, sendo um espaço externo onde ficaram expostos os modelos tridimensionais e onde eram realizadas as experiências, e, outro espaço fechado, onde eram apresentados os vídeos explicativos e o desenvolvimento dos jogos.

Após a realização da amostra de ciências os educandos das escolas A e B responderam ao questionário que tinha por objetivo investigar a percepção dos mesmos sobre o trabalho desenvolvido. Foram destacadas nesse artigo as seguintes questóes:

1. O conteúdo apresentado pelos educandos do IFRJ já era de seu conhecimento?

2. A apresentação dos trabalhos contribuiu para seu aprendizado?

3. Você classificaria a atividade realizada pelos educandos do IFJR na sua escola como:

a) insuficiente b) regular c) boa d) muito boa.

Abaixo uma tabela que demonstra o resultado da pesquisa feita com os educandos que participaram da amostra de ciências.

\section{AVALIAÇÁO DA AMOSTRA DE CIÊNCIAS}

\begin{tabular}{|c|c|c|c|c|c|c|}
\hline \multirow[t]{2}{*}{ Número de alunos } & \multicolumn{2}{|c|}{ Questão 1} & \multicolumn{2}{|c|}{ Questão 2} & \multirow{2}{*}{\multicolumn{2}{|c|}{$\begin{array}{c}\text { Questão } 3 \\
\text { Itens: }\end{array}$}} \\
\hline & Sim & Não & Sim & Não & & \\
\hline \multirow[t]{4}{*}{ Escola A: 59} & 48 & 11 & 55 & 4 & a) 0 & $0 \%$ \\
\hline & & & & & b) 2 & $-\quad 3 \%$ \\
\hline & $81 \%$ & $19 \%$ & $93 \%$ & $7 \%$ & c) 19 & $-32 \%$ \\
\hline & & & & & d) 38 & $-65 \%$ \\
\hline \multirow[t]{4}{*}{ Escola B: 52} & 44 & 8 & 48 & 4 & a) 0 & $0 \%$ \\
\hline & & & & & b) 3 & $6 \%$ \\
\hline & $84 \%$ & $16 \%$ & $92 \%$ & $8 \%$ & c) 18 & $35 \%$ \\
\hline & & & & & d) 31 & $59 \%$ \\
\hline
\end{tabular}

$\mathrm{Na}$ escola A foram pesquisados 59 educandos e na escola B 52. Todos cursavam o Ensino Médio e as respostas dadas permitem algumas análises. Com relação à questão 1 pode-se perceber que a maior parte dos educandos já tinha estudado o conteúdo apresentado na amostra de ciências (estrutura e função do núcleo de uma célula eucariótica). Isso indica que esse conteúdo é abordado nas diferentes escolas, no entanto, os alunos afirmam que a atividade realizada contribuiu para o seu aprendizado. Esse dado é obtido ao se analisar as respostas dadas na questão 2, onde, em ambas as escolas o percentual de respostas positivas foi maior que $90 \%$. Isso pode demonstrar que a forma diferenciada da apresentação do conteúdo pode ter sido decisiva nesse processo, pois ela contou com várias estratégias que permitiram uma visão do conhecimento de forma mais integrada, evitando uma imagem irreal e fragmentada da Ciência e reduzindo-a a simples memorização (ROGADO, 2004; MARIN, 1998). 
Por outro lado a realizaçáo da amostra de ciências permitiu uma integração entre os estudantes das duas diferentes escolas, possibilitando um processo dinâmico e descontraído, onde apresentaçáo de modelos explicativos, a realização de experimentos, jogos e música permitiram um momento de aprendizagem prazerosa o que levou uma parte considerável dos educandos das duas escolas a classificar a atividade como boa ou muito boa. Pode-se dizer que houve um importante ato de divulgação científica nas escolas visitadas. Alguns educandos dessas escolas se mostraram surpresos ao ver a montagem de um trabalho em espaços disponíveis da escola como: pátio, sala de vídeo, corredores. Isso demonstrou que essa atividade pode ser realizada em qualquer escola, pois náo demanda a utilização de espaços ou equipamentos sofisticados.

Os resultados também indicam que a utilização de modelos explicativos, construídos pelos próprios educandos (KRASILCHICK, 2004) é uma estratégia importante para a compreensão de alguns conteúdos, pois os discentes que apresentaram a amostra de ciência declararam, ao final da mesma, que grande parte do conteúdo que estavam apresentando para os colegas das outras escolas, foram aprofundados durante a montagem dos modelos explicativos.

Além dos resultados apresentados, cabe destacar que a apresentação do projeto na II Sematec-Sul IFRJ-VR permitiu uma divulgação do conhecimento científico junto à comunidade escolar. Informaçóes relevantes sobre o câncer e as instituiçóes que fazem tratamento e acompanhamento de pessoas acometidas por essa doença na cidade e região, permitiu uma contribuição para a popularização da ciência junto à comunidade. Nesse aspecto os alunos conseguiram dar um passo importante ao fazer uma relação entre o conteúdo estudado e os desdobramentos desses na investigação de uma doença desafiadora e as possíveis tecnologias desenvolvidas para o tratamento dessa enfermidade e as dificuldades enfrentadas para que essa tecnologia seja universalizada junto a população mais carente.

Além disso, deve-se destacar a visita aos centros de apoio aos portadores de câncer na cidade de Volta Redonda, onde os estudantes puderam conhecer a realidade dos portadores e familiares, que muitas vezes vêm de cidades distantes e necessitam contar com a solidariedade das pessoas que fazem doação de alimentos, roupas, utensílios e seus voluntários que doam seu trabalho para manutenção dessas instituições. Com isso certamente pode-se estabelecer uma prática de CTS (Ciência Tecnologia e Sociedade) permitindo uma inserção da escola nos desafios tecnológicos e suas implicações sociais. Portanto, foi possível perceber a relevância de aproximar o educando da ciência e da tecnologia em todas as dimensóes da sociedade, oportunizando a ele uma concepção ampla e social do contexto científico-tecnológico (PCNEMs).

\section{BIBLIOGRAFIA}

1. AngOTTI, J. A.; AUTH, M. A. Ciência e Tecnologia: Implicaçốes Sociais e o papel da Educação. Ciência e Educação, vol.7, n.1, 2001, p.15-27.

2. AUSUBEL, D. P. A aprendizagem significativa: a teoria de David Ausubel. São Paulo: Moraes, 1982.

3. BARBIER, R. A pesquisa-açáo. Brasília: Plano Editora, 2002.

4. BRASIL. Secretaria de Educação Fundamental. Parâmetros curriculares nacionais: Ciências Naturais/Secretaria de Educação Fundamental. - Brasília: MEC/SEF, 1999.

5. CERTEAU, Michel. A invençáo do cotidiano: 1. artes de fazer. 7 ed. Petrópolis, RJ: Vozes, 1994.

6. GIORDAN, A. \& VECCHI, G. de. As origens do saber: das concepçóes dos aprendentes aos conceitos científicos. $2^{\text {a }}$ ed. Porto Alegre: Artes Médicas, 1996.

7. JUSTINA, L. A. D.; FERLA, M. R. A utilizaçáo de modelos didáticos no ensino de Genética. Exemplo de representaçáo de Compactaçáo do DNA Eucarioto. Revista Arquivos do Mudi, Maringá, 2006.

8. KRASILCHICK, M. Prática de Ensino de Ciências. São Paulo: EPU/Edusp, 2004.

9. LORENZINI, N.M.P.; ANJOS, C.R.. Teoria de modelos e o ensino de biologia o diálogo entre teoria e prática. Encontro Perspectivas do ensino de biologia. São Paulo: Graf. FE. 2004

10. MARIN, Alda Junqueira. Desenvolvimento profissional docente: início de um processo centrado na escola. In VEIGA, Ilma Passos A. Caminhos da profissionalizaçâo do magistério. Campinas: Papirus, 1998.OLIVEIRA, Inês Barbosa. Currículos praticados: entre a regulação e a emancipação. Rio de Janeiro. DP\&A, 2003.

11. ROGADO, J. A grandeza quantidade de matéria e a sua unidade, o mol: algumas consideraçóes sobre dificuldades de ensino aprendizagem. Revista Ciência e Educação, Bauru, v.10, n.1, 2004.

Endereço para Correspondência:

Marcelo Paraiso Alves

Endereço - Rua: 62, n 548

Bairro Sessenta - Volta Redonda - RJ

CEP: $27.265-550$ 